\title{
Gender \& Kepemimpinan Perpustakaan Perguruan Tinggi Muhammadiyah: Inovasi Layanan di Masa Pandemi Covid-19
}

\author{
ARAS SATRIA AGUSTA \\ IIS-Kosentrasi Ilmu Perpustakaan dan Informasi, UIN Sunan Kalijaga Yogyakarta \\ Jl. Laksda Adisucipto, Daerah Istimewa Yogyakarta 55281 \\ e-mail:* arassatria.agusta@gmail.com
}

\begin{abstract}
Introduction. This article is entitled "Gender \& Leadership of Muhammadiyah Higher Education Libraries: Service Innovation during the Covid-19 Pandemic." The purpose of writing is to systematically describe and interpret gender and leadership in bringing new innovations in library services during the Covid-19 pandemic in the form of transformative policies.

Research Methods. In this article, the author uses descriptive qualitative methods with constructivist and critical interpretive efforts in seeing the phenomena that occur, by formulating several crucial issues which are summarized in the question: Why is genderization of library leadership important to produce new innovations in services in times of crisis? Meanwhile, the data were collected by means of online observation, online interviews and call interviews

Results and Discussion. The results of the research in this article show that the role of gender feminism in library leadership during the Covid-19 pandemic crisis is very urgent in relation to efforts to transform service change as protecting the existence of libraries. The head of the Muhammadiyah College library plays a professional and maternal role in making a policy (democratic and transparent). In crisis conditions, transformation is carried out by utilizing both forms of service, namely conventional (covid-19 protocol) and digital (wa, instagram, zoom, repository, and web library). So, that these efforts are very intersubjective to become novelty for Muhammadiyah Higher Education libraries in an effort to transform services that are more creative, innovative, and relevant from various conditions.

Conclusions and recommendations. From these results, to bring existence to the Muhammadiyah Higher Education library in various intersubjective conditions requires relevance between effective policies in line with the gender role of the head of the library. This is necessary for the library to consider more carefully the policies to be taken so that it is user-oriented, because it will affect the existence of the library in the future in facing various situations.
\end{abstract}

Keywords: Gender, Leadership, Transformation, Innovation, Library, PT

Muhammadiyah

\begin{abstract}
ABSTRAK
Pendahuluan. Artikel ini berjudul "Gender \& Kepemimpinan Perpustakaan Perguruan Tinggi Muhammadiyah: Inovasi Layanan di Masa Pandemi Covid-19." Tujuan dalam penulisan ialah untuk mendeskripsikan secara sistematis dan menginterprestasikan terhadap gender \& kepemimpinan didalam membawa inovasi baru layanan perpustakaan dimasa pandemic covid-19 dalam bentuk kebijakan yang transformative.

Metode Penelitian. Dalam artikel ini penulis menggunakan metode Kualitatif desktiptif dengan upaya konstruktivis dan interpretative kritis dalam melihat fenomena yang terjadi,
\end{abstract}


dengan dirumuskan beberapa isu krusial yang dirangkum dalam pertanyaan: Mengapa genderisasi kepemimpinan perpustakaan penting untuk melahirkan inovasi baru dalam layanan di masa krisis? Sementara data dikumpulkan dengan cara observasi online, online interview dan call interview.

Hasil dan Pembahasan. Hasil penelitian dalam artikel ini memperlihatkan bahwa peranan gender feminism kepemimpinan perpustakaan di masa krisis pandemic covid-19 sangat urgensi berkaitan dengan upaya transformasi pada perubahan layanan sebagai protect terhadap eksistensi perpustakaan. Kepala perpustakaan Perguruan Tinggi Muhammadiyah memainkan peranan profesional dan peranan keibuan dalam mengambil suatu kebijakan (demokratis dan transparan). Dalam kondisi krisis, transformasi dilakukan dengan memanfaatkan kedua bentuk layanan yakni konvensional (protocol covid-19) dan digital (wa, instagram, zoom, repository, dan web perpustakaan). Sehingga upaya tersebut sangat intersubjektif menjadi novelty bagi perpustakaan Perguruan Tinggi Muhammadiyah dalam upaya mentransformasikan layanan yang lebih kreatif, inovatif, dan relevan dari berbagai kondisi.

Kesimpulan dan Saran. Dari hasil tersebut, untuk membawa eksistensi bagi perpustakaan Perguruan Tinggi Muhammadiyah dalam berbagai kondisi yang intersubjektif di perlukan kerelevanan antara kebijakan yang efektif berselarasan dengan peranan gender feminism kepala perpustakaan. Hal ini diperlukan perpustakaan untuk mempertimbangkan lebih seksama terhadap kebijakan yang akan diambil sehingga berorientasi pada pengguna, karena akan mempengaruhi eksistensi dari perpustakaan dimasa mendatang dalam menghadapi berbagai situasi.

Kata Kunci: Gender, Kepemimpinan, Transformasi, Inovasi, Perpustakaan, PT Muhammadiyah

\section{A. PENDAHULUAN}

Hentakan peristiwa pandemic covid-19 telah menjadi suatu bahan diskusi yang menarik di berbagai interdisiplin keilmuan. Banyak transformasi ataupun perubahan terjadi secara revolusioner terhadap berbagai lembaga baik formal maupun informal, hal ini menginsyaratkan bahwa gejolak perubahan benar adanya sebagai bentuk upaya kesadaran diri dalam mempersiapkan protect menghadapi segala perubahan tersebut. Seperti situasi krisis saat ini (pandemi covid-19) yang melanda di seluruh penjuru dunia juga berdampak pada lembaga perpustakaan di perguruan tinggi, sehingga ada upaya pembatasan dari aktivitas interaksi. Perpustakaan yang notabennya merupakan lembaga dengan interaksi manusia cukup beragam dibatasi secara konvensional. Sehingga perpustakaan sebagai wadah untuk pendidikan, penelitian, dan pusat informasi bagi pengetahuan 
masyarakat secara umum sangat urgen untuk dapat memainkan peranannya dengan suatu transformasi layanan yang efektif dimasa krisis. ${ }^{1}$

Krusialnya kehadiran perpustakaan di masa krisis akan bersinggungan dengan beragam teknologi informasi dan komunikasi hal ini tidak bisa terelakkan. Sehingga perubahan dimasa krisis akan menjadi suatu diskursus terhadap kesiapan perpustakaan dalam menerapkan teknologi tersebut secara optimal sebagai transformasi pada layanannya. Penerapan ini menjadikan sorotan utama terhadap peranan kuasa yang dimainkan oleh pimpinan perpustakaan. ${ }^{2}$ Melihat peranan kuasa seorang pimpinan perpustakaan, ${ }^{3}$ tentunya menjadi biasa apabila seorang pemimpin "laki-laki”" sebagai pengambil keputusan dan kebijakan. Akan tetapi lebih istimewa jika keputusan dan kebijakan tersebut diambil dengan peranan kuasa pemimpin "perempuan", sehingga akan tergambar adanya kesetaraan gender dalam suatu kuasa kepemimpinan.

Gender merupakan pemaknaan terhadap kesetaraan antara laki-laki dan perempuan. ${ }^{4}$ Sebagai contoh dari penerapan gender pada institusi pendidikan tinggi seperti di perpustakaan Universitas Nazarbayev, perpustakaan Perguruan Tinggi Muhammadiyah, dan perpustakaan UIN Sunan Kalijaga Yogyakarta. Lembaga tersebut telah memberikan akses yang sama pada perempuan untuk memimpin perpustakaan. Dalam artian tidak ada diskriminasi berdasarkan ras, agama, gender, ${ }^{5}$ kemampuan fisik, dan status sosial. Sehingga dari hal itu akan menciptakan keberagaman dan inklusivitas. ${ }^{6}$

Dengan adanya keberagaman dan inklusivitas pada perpustakaan, maka diharapkan kebijakan dari karakteristik gender feminism seorang kepala

\footnotetext{
${ }^{1}$ Ashiq, Murtaza. Rehman, Shafiq Ur \& Batool, Syeda Hina. “Academic library leaders' conceptions of library leadership in Pakistan." Malaysian Journal of Library \& Information Science, 24 (2), 55-71. doi:0.22452/mjlis.vol24no2.4. 2019.

${ }^{2}$ Foucault, M. Menggugat Sejarah Ide (terj. Inyiak Ridwan Muzir). (Yogyakarta: Ircisod, 2012). 2015).

${ }^{3}$ Laugu, N. Representasi Kuasa dalam Pengelolaan Pengetahuan (Yogyakarta: Gapernur pres,

${ }^{4}$ Miswanto, Agus. "Gender Equality Rights Discourse in Indonesia: Muhammadiyah Reading Models." Atlantis Press SARI: Advances in Social Science, Education and Humanities Research, volume 436, 327-332, 2020.

5 Yap, Marmol Joseph \& Kamilova, Yelizaveta. "Toward Becoming an Inclusive Library: Integrating Sustainable Development Goal 5 in the library Agenda." Emerald: Vol. 41 No. 2/3, 2020. 53-66.

${ }^{6}$ Bilyalov, D. "Organizational socialization and job satisfaction of faculty at Nazarbayev University in Kazakhstan.” European Education, Vol. 50 No. 3, 2018. 229-248, doi: 10.1080/ 10564934.2017.1401436.
} 
perpustakaan dapat membawa keberlangsungan yang produktif di masa krisis, ${ }^{7}$ seperti transformasi layanan perpustakaan dengan pemanfaatan media teknologi informai dan komunikasi. Oleh karenanya, untuk menentukan fokus pada tema yang luas ini, peneliti akan menginterprestasikan terhadap gender feminism kepala perpustakaan Perguruan Tinggi Muhammadiyah dalam mentransformasikan aktivitas dan layanan di masa pandemic covid-19.

\section{B. KAJIAN TEORI}

\section{Gender dan Kepemimpinan}

Perspektif sentral pada gender menawarkan suatu konsep dimana perempuan mengembangkan gaya kepemimpinan feminisme dan laki-laki mengadopsi gaya kepemimpinan maskulin. ${ }^{8}$ Pada beberapa literature juga telah ditemukan terhadap penekanan perilaku dari pemimpin, seperti maskulinitas dicirikan dalam penggunaannya pada permulaan struktur, ${ }^{9}$ sementara feminisme lebih banyak digunakan dalam menunjukkan pertimbangan. ${ }^{10}$ Inisiasi dari struktur tersebut terdiri dari tingkah laku yang berorientasi pada tujuan serta adanya suatu simpati pada bawahan, partisipasi, kepuasan, dan persahabatan. Sementara pada laki-laki lebih menonjolkan diri, agresif, dan kasar dalam sikap dan bahasa dibandingkan wanita. ${ }^{11}$

Feminisme terdiri dari perilaku yang berhubungan dengan dorongan, menghargai dan memampukan orang lain dalam mencapai tujuan pada organisasi, dalam artian peranan karakteristik antara laki-laki dan perempuan akan mencirikan terhadap kepribadian pola kepemimpinannya yang transformative. Dari penelitian

\footnotetext{
${ }^{7}$ Enloe , Cynthia. Bananas, Beaches and Bases: Making Feminist Sense of International Politics. (Berkeley University of California Press, 2014).

${ }^{8}$ Eagly, A.H., Makhijani, M.G. and Klonsky, B.G. "Gender and the evaluation of leaders: a metaanalysis.” Psychological Bulletin, Vol. 111, 1992, 3-22.

${ }^{9}$ Spence, J.T. and Helmreich, R.L. Masculinity and Feminity: Their Psychological Dimensions, Correlates, and Antecedents (Austin, TX: University of Texas Press, 1978).

${ }^{10}$ Williams, J.E. and Best, D.L. Measuring Sex Stereotypes: A Thirty Nation Study (Beverly Hills, CA: Sage, 1982).

${ }^{11}$ Brandt, Tiina \& Laiho, Maarit. "Gender and Personality in Transformational Leadership Context: An Examination of Leader and Subordinate Perspectives. ” Emerald: Leadership \& Organization Development Journal Vol. 34 No. 1, 2013, 44-66.
} 
Eagly mengungkapkan bahwa, pemimpin perempuan lebih transformative dan menerapkan konsep contigent reward dibandingkan dengan pemimpin laki-laki. ${ }^{12}$

\section{Karakteristik Kepemimpinan Transformatif di Masa Krisis (Covid-19)}

Peranan pemimpin sangat menentukan terhadap protect dan keberlangsungan institusi termasuk didalamnya mengupayakan inovasi baru. Peranan tersebut selaras dengan modernitas yang menuntut perubahan, begitupula pada lembaga perpustakaan tentunya tidak kebal terhadap gejolak perubahan tersebut. Kepemimpinan transformasi dinilai mampu untuk mengikuti perubahan dalam tuntutan profesionalisme dan mampu dalam beradaptasi dengan perkembangan teknologi informasi dan komunikasi. ${ }^{13}$

Karakteristik perubahan dalam lingkungan informasi serta peningkatan skala informasi membuat perpustakaan untuk lebih kritis dalam mengevaluasi diri. Selaras dengan itu, Purwanto membuat suatu indikator dimana pemimpin transformative di upayakan bisa melakukan cara untuk mendorong bawahan sadar akan hasil kinerja, mendorong bawahan untuk lebih mementingkan organisasi di atas kepentingan sendiri, dan mampu mengaktifkan kebutuhan setiap bawahan pada consumption a higher. ${ }^{14}$

Praktik dalam transformasi kepemimpinan yang berselarasan dengan digitalisasi dan visualisasi mengambarkan terhadap praktik kuasa ${ }^{15}$ seorang pemimpin perpustakaan untuk dapat mengubah layanan perpustakaan pada orientasi perubahan nilai, keterampilan dalam mempengaruhi dan negosiasi, ${ }^{16}$ memiliki kreativitas serta inovasi, mengerti pemasaran dan manajemen informasi digital, ${ }^{17}$ dan mampu berkolaborasi lebih efektif, ${ }^{18}$ sehingga akan membawa

\footnotetext{
12 Eagly, A.H., Johannesen-Schmidt, M.C. and van Engen, M. “Transformational, trasactional, and laissez-faire leadership: a meta-analysis comparing women and men”. Emerald: Psychological Bulletin, Vol. 95, 2003, 69-91.

${ }^{13}$ Husna, Jazimatul. “Transformasi Kepemimpinan Bagi pusTaKawan di era digital.” Libraria, Vol. 7, No. 1, 2019. 1-18.

${ }^{14}$ Purwanto, Budi. "Hubungan Antara Gaya Kepemimpinan Tranformasional Dan Transaksional Dengan Komitmen Terhadap Organisasi," Sosiohumanika 14, no. 1 (2001), 245-63.

${ }^{15}$ Foucault, M. Menggugat Sejarah Ide (terj. Inyiak Ridwan Muzir). (Yogyakarta: Ircisod, 2012).

16 Johnson, Catherine A. "Library and Information Science Education in Developing Countries." The International Information \& Library Review 39, no. 2, 2007. 64-71.

${ }^{17}$ Nicholas, David, and Ian Rowlands. Digital Consumers: Reshaping the Information Professions. (London: Facet Publishing, 2008).

${ }^{18}$ Husna, Jazimatul, 2019.
} 
perpustakaan pada protect dan keberlangsungannya lebih produktif. ${ }^{19}$ Dalam hal itu, gaya kepemimpinan transformative diharapakan sebagai suatu proses sosial dimana seseorang dapat untuk meminta bantuan serta dukungan orang lain dalam pencapaian tugas bersama. ${ }^{20}$ Terlebih dalam upaya menciptakan layanan baru yang lebih produktif dan efektif.

\section{Inovasi Layanan Perpustakaan di Masa Krisis (Covid-19)}

Inovasi layanan perpustakaan tidak terlepas dari upaya implementasi ideologis seorang pemimpin untuk bertransformasi. ${ }^{21}$ Inovasi merupakan salah satu bentuk kebaharuan yang menjadi identitas didalam merubah suatu konsep wacana transformatif. $^{22}$ Macdonell, menyatakan wacana transformasi merupakan suatu arena dimana khalayak berpikir dengan jalan tertentu. ${ }^{23}$ Seperti dengan memanfaatkan media komunikasi dan informasi sebagai jalan inovasi pada tranformasi layanan perpustakaan di masa krisis. ${ }^{24}$

Pemanfaatan media tersebut sebagai bentuk pembatasan terhadap perubahan layanan perpustakaan dalam mengadapai krisis (pandemic covid-19), dimana segala upaya telah dibatasi secara konvensional dan beralih pada new normal dengan memanfaatkan media teknologi sebagai inovasi baru. Fokus sasaran transformasi perpustakaan didalam memberikan layanan informasi yang inovatif tidak terlepas dari social network. ${ }^{25}$ Sehingga, pemanfaatan media komunikasi dan informasi yang dipadukan dengan network ${ }^{26}$ akan menciptakan layanan baru berbasis interaksi secara daring. ${ }^{27}$ Hal ini akan membawa kebaharuan pada layanan

\footnotetext{
${ }^{19}$ Laugu, N. (2015). Representasi Kuasa dalam Pengelolaan Pengetahuan (Yogyakarta: Gapernur pres, 2015).

${ }^{20}$ Chemers, Martin M. An Integrative Theory of Leadership. (Lawrence: Erlbaum Associates, 1997), 11.

${ }^{21}$ Evans, G. Edward; Intner, Sheila S.; Weihs, Jean. Introduction to technical services. (Colorado: Libraries Unlimited, 2002).

${ }^{22}$ Foucault. The Archeology of Knowledge, 1972. Dalam buku Eriyanto. Analisis Wcana: Pengantar Analisis Teks Media (Yogyakarta: LKis Printing Cemerlang, 2015), 73.

${ }^{23}$ Macdonell. Theories of Discourse (Oxfoard: Blackwell, 1986), 87.

${ }^{24}$ Castells, M. "the Rise of the Network Society." Vol. I. Malden, Ma: Wiley Blackwell, 2010b.

${ }^{25}$ Nasrullah, Rulli. Media Sosial: Perspektif Komunikasi, Budaya, dan Sosioteknologi (Bandung: Simbiosa Rekatama Media, 2017)), 113.

${ }^{26}$ Wood, A.F \& Smith, M.J. Online Communication, Lingking Technology, Identity \& Cultur (Mahwah, NJ: Lawrence Erlbaum, 2005), 129.

${ }^{27}$ Baym, N, K. The Emergence Of Online Community. In Cybersociety 2.0: Revisiting ComputerMediated Communication And Community (Thousand Oaks, Ca: SAGE Publications, Ltd, 1998), 35-68.
} 
perpustakaan didalam memenuhi informasi yang lebih efektif dan cepat. ${ }^{28}$ Terlebih dalam penerapan inovasi baru dimasa krisis pandemic covid-19.

\section{METODE PENELITIAN}

Dalam peristiwa pandemic covid-19 yang banyak menyita berbagai perhatian masyarakat terlebih dalam dunia akademik seperti lembaga perpustakaan, maka akan tercipta suatu pandangan baru khusnya pada peranan gender dalam transformasi kepemimpinan menghadapi situasi sulit ini. Oleh karenanya, penelitian ini akan mendeskripsikan secara kualitatif dengan dirumuskan beberapa isu krusial yang dirangkum dalam pertanyaan: "Mengapa genderisasi kepemimpinan perpustakaan penting untuk melahirkan inovasi baru dalam layanan di masa krisis?"

Untuk menjawab hal tersebut, penelitian ini menggunakan jenis penelitian kualitatif deskriptif dengan suatu paradigma konstruktivis dan interpretative kritis dalam melihat fenomena yang terjadi. ${ }^{29}$ Adapun teknik pengumpulan data dilakukan dengan cara triangulasi (gabungan), analisis data bersifat induktif, dan hasil penelitian lebih menekankan pada generalisasi. ${ }^{30}$

Dalam penelitian ini, data dikumpulkan dengan cara observasi online, online interview dan call interview. Data utama melalui call interview melalui media komunikasi. Sementara dalam penguatan maka dilakukan online interview via google from dan informan diminta memberikan komentar/jawaban secara sistematis dalam bentuk chat. Hal ini digunakan karena dimasa pandemic covid-19 yang membatasi dalam interaksi fisik, sehingga mengalami keterbatasan fisik untuk melakukan interview. Teknik analisis menggunakan pendekatan dari Miles dan Huberman yang terdiri dari reduction, data display, dan verification dengan pengujian kreadibilitas data berdasarkan pada triangulasi sumber, triangulasi

\footnotetext{
${ }^{28}$ Prasasti, Giovani Dio. UNESCO: Penutupan sekolah akibat covid-19 berdampak pada 290 juta pelajar di dunia. Retrieved from liputan6.com: liputan6.com/health/read/4195275/unesco-penutupan-sekolahakibat-covid-19-berdampak-pada-290-juta-pelajar-di-dunia, 2020

${ }^{29}$ Laugu, Nurdin. Ideology Contestation in Management of University Library Development. JSW (Jurnal Sosiologi Walisongo), 3(2), 179-194 . doi:10.21580/jsw.2019.3.2.4266, 2019.

${ }^{30}$ Sugiyono, Metode Penelitian Pendidikan : Pendekatan Kuantitatif, Kualitatif, dan R\&D (Bandung: Alfabeta, 2015), 15 .
} 
teknik, dan triangulasi waktu. ${ }^{31}$ Adapun informan dalam penelitian ini ialah kepala perpustakaan dan pustakawan/staf perpustakaan di perguruan tinggi Muhammadiyah.

\section{HASIL}

\section{Gender Feminisme di Perpustakaan PT Muhammadiyah}

Feminisme dalam Persyarikatan Muhammadiyah bukanlah suatu diskursus baru, dalam konteks sejarah Muhammadiyah telah mempraktekkan terhadap peran perempuan dalam kepemimpinan seperti Aisyiyah dan Nasyiatul Aisyiyah. ${ }^{32}$ Hal ini memperlihatkan adanya kesetaraan gender yang dibawa Muhammadiyah pada organisasinya, termasuk didalamnya lembaga Pendidikan Tinggi seperti Perpustakaan Perguruan Tinggi Muhammadiyah yang mempraktekkan upaya kesetaraan gender tersebut dalam memajukan instansi tanpa intimidasi.

Kepemimpinan feminism perpustakaan Perguruan Tinggi Muhammadiyah membawa suatu nilai produktifitas dalam menghadapi pandemic untuk menjadi suatu bagian sentral menyalurkan informasi bagi penggunanya, sehingga perpustakaan PT Muhammadiyah dapat untuk menerapkan prinsip-prinsip kebutuhan sosial bagi terpenuhinya informasi kepada pengguna secapa efektif. Hal ini memberikan suatu bentuk produktifitas dimasa krisis bagi kepala perpustakaan, sehingga setiap kebijakan akan mengambarkan terhadap peranan indikator gender yang dimilikinya. Seperti yang disampaikan informan 3, informan 8, dan informan 5 berikut

“Menurut saya mau pemimpinnya perempuan atau pun laki-laki sama saja tidak ada yang membedakan. Untuk kepala perpustakaan saya yang merupakan seorang perempuan, beliau adalah pemimpin yg demokratis dan idealis tidak mencampur adukkan urusan pribadi dengan pekerjaan dan tidak terbawa perasaan dalam penyelesaian masalah saat bekerja. Dengan adanya sifat feminis kepala perpustakaan, maka saya sebagai pustakawan merasakan adanya perhatian plus dari keppus, sehingga kebijakan yang beliau ambil membuat saya lebih termotivasi untuk lebih baik dalam menjalankannya dimasa corona ini.,

\footnotetext{
${ }^{31}$ Sugiyono. Metode Penelitian Kombinasi (mixed methods) (Bandung: Alfabeta, 2017), 331-357.

32 Handayani, Indah Tri dan Rosmilawati, Srie. "Peran Perempuan Muhammadiyah dalam Kepemimpinan dan Politik di Kalimantan Tengah.” Pencerah Publik,Vol.6 Issue 2, 2019. 32-42.
} 
Sementara informan 4 menyatakan bahwa perpustakaan yang dipimpin oleh seorang perempuan akan lebih unggul seperti termuat dalam hasil wawancara berikut

"Justru bagus kalau suatu instansi dipimpin oleh seorang wanita. Karena wanita itu lebih unggul dalam hal manajemen."

Dari perhatian feminism kepala perpustakaan PT Muhammadiyah telah memperlihatkan secara substantive terhadap peranan gender yang di perankannya sebagai seorang pemimpin. Dalam produktifitas kepemimpinan feminism pada perpustakaan Perguruan Tinggi Muhammadiyah, akan memberi suatu pemaknaan bahwa perempuan bisa produktif dan membawa inovasi baru terhadap lembaga yang dipimpinya, dengan feminism-nya ia lebih unggul dalam memperlaukan sesuatu hal, ini diperlihatkan dari gaya kepemimpinan lembaga perpustakaan yang dipimpinnya.

\section{Gaya Kepemimpinan Perpustakaan PT Muhammadiyah}

Sistem kerja pada perpustakaan yang telah diubah dari konvensional menjadi work from home (WHF) bagi sebagian pustakawan dan staf perpustkaan adalah hal yang baru, sehingga perlu kesiapan dan adaptasi terhadap kebutuhan selama bekerja. Dalam hal ini, gaya kepemimpina di perpustakaan Perguruan Tinggi Muhammadiyah menerapkan gaya kepemimpinan yang transparansi dan demokratis. Dimana kepala perpustakaan memiliki program dan kebijakan yang mengatur secara profesional atas hak dan kewajikan bagi pustakawan dan anggota perpustakaan secara musyawarah dan sesuai dengan sistem peraturan yang berlaku, dalam artian kepala perpustakaan menjunjung tinggi professionalitas dan satu rasa dalam mencapai tujuan.

Sehingga dari upaya professionalitas tersebut akan mengatasi terhadap masalah secara cepat oleh perpustakaan. Keterlibatan pegawai (pustakawan/staf) perpustakaan memperlihatkan terhadap pola gaya kepemimpinan yang dibangun selalu berorientasi pada kebijakan mufakat. Dalam artian, gaya kepemimpinan feminism kepala perpustakaan dapat merangkul pegawai secara kekeluargaan, sehingga dari hal itu dapat untuk mencapai tujuan bersama dalam menghadapi masa krisis pandemic covid-19 dengan musyawarah dan melibatkan segenap unsur 
kepegawaian. Keterlibatan tersebut dapat memaksimalkan dalam pengambilan keputusan, seperti yang disampaikan oleh informan 1, informan 7, dan informan 8

"Pegambilan keputusan tetap dengan cara musyawarah untuk mufakat"

"Keputusan yang di ambil secara mufakat maka akan menghasilkan hasil yang maksimal”

“Karena keberhasilan dari pada suatu perpustakaan terletak dari kebijakan-kebijakan yang berhasil diterapkan oleh kepala perpustakaan (pimpinan) dengan cara musyawarah",

Hal ini juga diperkuat oleh beberapa informan, dimana ia menyampaikan bahwa kepala perpustakaan berpengaruh dan dikagumi dengan gaya kepemimpinannya yang professional dan perhatian. Dalam konteks ini, gender feminism kepala perpustakaan menunjukkan peranannya dalam tanggungjawab sebagai pimpinan perpustakaan dan tidak melupakan kemanusiaan dan perhatian terhadap kesulitan yang di hadapi. Dari upaya tersebut, tentunya gaya kepemimpinan tranparansi dan demokratis yang dipraktikkan oleh kepala perpustakaan tidak terlepas dari keprofesional ideologi Persyarikatan Muhammadiyah. Sehingga implementasi arena wacana transformasi dimasa krisis dapat untuk dilaksanakan oleh perpustakaan dari kebijakan-kebijakannya. Maka pelaksanaannya membutuhkan suatu inovasi yang transformative, dimana dengan inovasi tersebut kepala perpustakaan dapat menggerakkan secara maksimal terhadap bawahannya untuk berkolaborasi dalam memenuhi tugas layanan informasi bagi segenap pengguna perpustakaan secara maksimal dan efektif dimasa krisis.

\section{Transformasi Layanan Perpustakaan PT Muhammadiyah}

Dimasa krisis pandemic covid-19 diperlukan inovasi dalam komunikasi yang efektif untuk mengatasi segala kerumitan dan perubahan. Inovasi komunikasi tersebut berserasan dengan era digital, dimana penggunaan media sosial sebagai pilihan terbaik bagi peningkatan layanan perpustakaan. Media sosial yang merupakan media interaktif memiliki kecepatan penyebaran sangat efektif dan tentunya relevan dengan kondisi sekarang. Kecepatan tersebut sangat membantu perpustakaan dalam promosi dan peningkatan akses layanan secara daring. Oleh sebab itu, peranan transformasi dalam penggunaan media sosial yang dibawa kepala perpustakaan akan menjadi kebijakan yang efektif dimasa krisis. 
Kebijakan inovatif dengan pemanfaatan media sosial dan layanan daring lainnya juga akan memaksimalkan upaya transformasi perpustakaan, sebagaimana tampak dari pengalaman informan 1, informan 7 dan informan 9.

"Pemanfaatan media sosial sudah dilakukan, namun layanan daring belum optimal"

"Dengan adanya layanan media sosial, pemustaka akan lebih mudah mencari informasi yang mereka butuhkan"

"Penggunaan media virtual seperti zoom dan repository sangat membantu pemustaka dalam mencari informasi dalam masa pendemi sekarang ini yang hanya belajar dari rumah"

Dengan adanya penggunaan media sosial dan layanan digital perpustakaan seperti zoom, repository, WA, dan Instagram. Maka perpustakaan telah membangun sistem komunikasi berbasis teknologi. Adanya penerapan media tersebut menjadi transformasi bagi layanan perpustakaan dimasa krisis. Dalam mengoptimalkan layanan yang berbasis orientasi kemanusiaan, maka perpustkaan juga menerapkan layanan konvensional (fisik) dengan mekanisme protokol penanganan covid-19.

Hal ini diterapkan karena setiap mahasiswa/pengguna perpustakaan memiliki latar belakang yang berbeda, seperti adanya keterbatasan ekonomi sehingga sulit untuk aktif mengakses layanan informasi perpustakaan secara daring, maka layanan konvensional juga diterapkan dengan sistem dan protocol Kesehatan.

Melihat hal itu, maka transformasi layanan perpustakaan (digital) tidak sepenuhnya dapat secara maksimal terealisasikan, akan tetapi upaya menuju pengoptimalan masih ditingkatkan dalam tahapan-tahapannya terlebih pada akses jaringan internet. Transformasi layanan ini sangat memungkinkan keberlangsungan dan eksistensi perpustakaan, bukan hanya dimasa pandemic tetapi berlaku dimasa mendatang. Oleh karenanya, dukungan terhadap kebijakan kepala perpustakaan dalam membawa inovasi diperlukan sinergitas dari segenap stakeholder Perguruan Tinggi Muhammadiyah, sehingga dapat untuk mengupayakan bagi perpustakaan mandiri dan produktif pada layanannya baik secara konvensional maupun digital dengan memanfaatkan berbagai media sosial lebih efektif dan relevan. 


\section{E. PEMBAHASAN}

Penelitian ini memperlihatkan bahwa gender feminism menjadi faktor yang mempengaruhi gaya kepemimpinan di perpustakaan Perguruan Tinggi Muhammadiyah. Hal ini di dasarkan dari berbagai tanggapan informan, maka dengan gaya feminism kepala perpustakaan diharapkan mampu membawa produktifitas pada lembaga yang di pimpinnya.

Kebijakan produktif relevan dengan gaya kepemimpinan yang di praktekkan oleh kepala perpustakaan. Sehingga mempengaruhi terhadap kebijakannya dimasa pandemic, hal ini akan bersinergi dengan keterlibatan peranannya sebagai professional (bekerja) dan perannya sebagai ibu rumah tangga (peduli/perasaan) yang mendominan terhadap pengambilan keputusan. Oleh karenanya, gaya kepemimpinan feminism sangat urgen dalam penetapan kebijakan dimasa krisis pandemic covid-19.

(Wisdom)

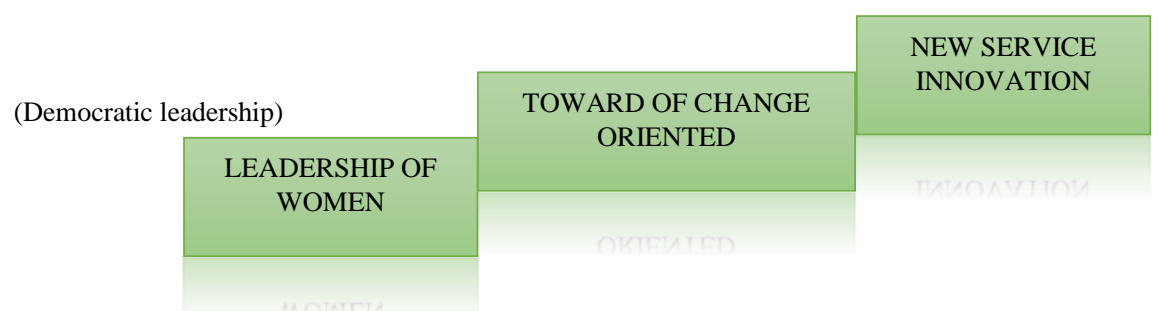

Figur 1: Gender feminism dan kepemipinan yang melahirkan inovasi layanan

Gaya kepemimpinan yang di terapkan perpusatakaan PT Muhammadiyah ialah gaya kepemimpinan demokratis dan transparansi yang bersinergi terhadap gender feminism kepala perpustakaan dengan selalu mengutamakan musyawarah mufakat (merupakan ideology Persyarikatan Muhammadiyah) dalam setiap pengambilan keputusan. Sehingga gaya kepemimpinan tersebut mengambarkan secara sistematis terhadap praktik kebijakan layanan yang lebih inovatif sesuai dengan kondisi yang relevan.

Kerelevanan produktifitas kebijakan kepala perpustakaan dalam menyikapi krisis ini ialah dengan cara mengupayakan transformasi layanan perpustakaan kedalam bentuk konvensional dengan penerapan protocol kesehatan (covid-19), dan penerapan layanan berbasis daring dengan memanfaatkan media sosial dan 
media digital seperti wa, instagram, zoom, dan layanan repository/web perpustakaan yang telah dimilikinya sebagai mediator untuk komunikasi, promosi, dan informasi layanan perpustakaan.

Atas hasil penelitian yang memperlihatkan transformasi layanan, maka dengan pemanfaatan media virtual akan berpengaruh dimasa mendatang sebagai transformasi dan inovasi layanan baru perpustakaan. Hal ini tidak bisa dilepaskan bagi perpustakaan dalam memenuhi informasi pengguna yang semakin literat dengan berbagai kondisi, karena media virtual sangat mengakar pada dimensi kehidupan masyarakat saat ini. Sehingga perpustakaan dengan layanan konvensional yang berbasis luring perlu untuk disinergikan peningkatannya dalam bentuk daring. Oleh sebab itu, peranan seorang kepala perpustakaan dalam membawa eksistensi bagi perpustakaannya perlu untuk meningkatkan upaya tersebut. Dari strategi ini akan membawa perpustakaan lebih dilirik oleh pengguna, dalam artian perpustakaan tidak monoton tetapi intersubjektif dan multilayanan dalam menerapkan inovasi-inovasi baru yang kreatif, efktif dan relevan dengan kondisi jangka panjang.

\section{F. KESIMPULAN}

Genderisasi kepemimpinan perpustakaan PT Muhammadiyah sangat urgen terhadap perubahan pada transformasi layanan di perpustakaan. Hal tersebut didasarkan pada peranan gender feminism yang berperan sebagai professional dalam lembaga dan peranan sebagai seorang ibu yang melibatkan perasaan dan perhatian dalam setiap keputusan yang diambil. Sehingga apa yang dimaksudkan dengan genderisasi feminism terhadap kepemimpinan perpustakaan PT Muhammadiyah akan membuka kran gaya kepemimpinan yang lebih demokratis dan transparan dengan selalu mengutamakan musyawarah mufakat dan keterlibatan emosional seorang feminism dalam setiap pengambilan keputusan pada berbagai situasi normal ataupun krisis.

Dalam masa krisis pandemic covid-19, peranan tersebut sangat krusial dipraktekkan, karena sangat relevan dengan kondisi dan peranan feminism seorang kepala perpustakaan. Hal ini akan membawa eksistensi bagi perpustakaan PT Muhammadiyah dalam berbagai kondisi yang intersubjektif. Sehingga kerelevanan 
tersebut akan membawa suatu kebijakan yang produktif seperti mentransformasikan layanan konvensional perpustakaan ke layanan digital dengan pemanfaatan media virtual seperti (wa, instagram, zoom, repository, dan web perpustakaan). Pada implementasi kebijakan tersebut, perpustakaan juga aktif dalam layanan konvensional. Dalam artian kepala perpustakaan selalu mempertimbangkan ragam kepentingan penggunanya, akan tetapi layanan konvensional di praktekkan dengan mematuhi protocol covid-19. Maka dalam merekonstruksi gaya kepemimpinan yang membawa inovasi lebih produktif, seorang kepala perpustakaan perlu untuk mempertimbangkan lebih seksama terhadap kebijakan yang akan diambil, karena hal tersebut menjadi bentuk eksistensi dari perpustakaan dimasa mendatang. Sehingga perlu terebosan baru yang kreatif, efektif dan relevan dari kepala perpustakaan menyikapi hal tersebut.

\section{REFERENCES}

Ashiq, Murtaza. Rehman, Shafiq Ur \& Batool, Syeda Hina. "Academic library leaders' conceptions of library leadership in Pakistan." Malaysian Journal of Library \& Information Science, 24(2), 55-71. 2019. doi:0.22452/mjlis.vol24no2.4.

Bass, B.M. Leadership and Performance Beyond Expectations. New York : Free Press, NY. 1985.

Baym, N, K. The Emergence Of Online Community. In Cybersociety 2.0: Revisiting Computer-Mediated Communication And Community. Thousand Oaks, Ca: SAGE Publications, Ltd, 1998.

Bilyalov, D. "Organizational socialization and job satisfaction of faculty at Nazarbayev University in Kazakhstan." European Education, Vol. 50 No. 3, 2018. 229-248, doi: 10.1080/ 10564934.2017.1401436.

Brandt, Tiina \& Laiho, Maarit. "Gender and Personality in Transformational Leadership Context: An Examination of Leader and Subordinate Perspectives.” Emerald: Leadership \& Organization Development Journal Vol. 34 No. 1, 2013.

Cao, Gaohui; Liang, Mengli; Li, Xuguang. "How to make the library smart? The conceptualization of the smart library." Emerald: Publishing Limited, Vol. 36 No. 5, 811-825. 2018.

Castells, M. "the Rise of the Network Society." Vol. I. Malden, Ma: Wiley Blackwell, 2010b.

Chemers, Martin M. An Integrative Theory of Leadership. Lawrence: Erlbaum Associates, 1997. 
Eagly, A.H., Johannesen-Schmidt, M.C. and van Engen, M. "Transformational, trasactional, and laissez-faire leadership: a meta-analysis comparing women and men”. Emerald: Psychological Bulletin, Vol. 95, 2003.

Eagly, A.H., Makhijani, M.G. and Klonsky, B.G. "Gender and the evaluation of leaders: a meta-analysis.” Psychological Bulletin, Vol. 111, 1992.

Enloe , Cynthia. Bananas, Beaches and Bases: Making Feminist Sense of International Politics. Berkeley University of California Press, 2014.

Evans, G. Edward; Intner, Sheila S.; Weihs, Jean. Introduction to technical services. Colorado: Libraries Unlimited, 2002.

Ferguson, T.W. "Female leadership and role congruity within the clergy: communal leaders experience no gender differences yet agentic women continue to suffer backlash." Sex Roles, Vol. 78 Nos 5/6, 2018.

Foucault, M. Menggugat Sejarah Ide (terj. Inyiak Ridwan Muzir). Yogyakarta: Ircisod, 2012.

Foucault. The Archeology of Knowledge, 1972. Dalam buku Eriyanto. Analisis Wcana: Pengantar Analisis Teks Media. Yogyakarta: LKis Printing Cemerlang, 2015.

Handayani, Indah Tri dan Rosmilawati, Srie. "Peran Perempuan Muhammadiyah dalam Kepemimpinan dan Politik di Kalimantan Tengah." Pencerah Publik,Vol.6 Issue 2, 2019.

Husna, Jazimatul. "Transformasi Kepemimpinan Bagi pusTaKawan di era digital.” Libraria, Vol. 7, No. 1, 2019.

Johnson, Catherine A. "Library and Information Science Education in Developing Countries." The International Information \& Library Review 39, no. 2, 2007

Laugu, Nurdin. Ideology Contestation in Management of University Library Development. JSW (Jurnal Sosiologi Walisongo), 3(2), 179-194 . doi:10.21580/jsw.2019.3.2.4266, 2019.

Laugu, N. Representasi Kuasa dalam Pengelolaan Pengetahuan. Yogyakarta: Gapernur pres, 2015

Macdonell. Theories of Discourse. Oxfoard: Blackwell, 1986.

Miswanto, Agus. "Gender Equality Rights Discourse in Indonesia: Muhammadiyah Reading Models." Atlantis Press SARI: Advances in Social Science, Education and Humanities Research, volume 436, 327-332, 2020.

Nasrullah, Rulli. Media Sosial: Perspektif Komunikasi, Budaya, dan Sosioteknologi. Bandung: Simbiosa Rekatama Media, 2017.

Nicholas, David, and Ian Rowlands. Digital Consumers: Reshaping the Information Professions. London: Facet Publishing, 2008. 